\title{
Symptom onset and \\ the socially sanctioned \\ pathway: the example of diet
}

Vol 11(1): 7-27

\author{
Jane Ogden \\ University of Surrey, Guildford, UK
}

\begin{abstract}
A B S T R AC T Theories of symptom perception do not explain symptom onset, nor why symptoms vary according to culture and time. This article attempts to explain cultural, temporal and individual variation in symptoms, and presents a new three-stage model of symptom onset. First, it is argued that tensions relating to issues of conflict and control arise as an individual interfaces with their social world and that this requires communication. Second, it is suggested that symptoms are embedded with culturally specific meanings which offer up a socially sanctioned pathway as a forum for communication. Third, if this pathway is appraised as personally relevant, the symptoms offered by the pathway will be adopted as the forum for communication. The resulting symptoms are therefore both culturally and personally meaningful. This model is derived from an analysis of the literature on diet, but is also offered as a means to understand the onset of other common symptoms.
\end{abstract}

KEYWORDS culture bound syndromes; diet; symptoms

A D D R E S S Jane Ogden, Department of Psychology, University of Surrey, Guildford, Surrey GU2 7XH, UK. [E-mail: j.ogden@surrey.ac.uk]

\section{Introduction}

Symptoms such as a headache, a cold, tiredness or stomach pain may indicate to the individual the possibility of a disease. Research, however, indicates that symptoms are not simply a matter of detection but are a perception relating to a range of psychological factors including mood and cognitions (Pennebaker, 1983). For example, Stegen at al. (2000) explored the impact of expectations on individuals' perception of low intensity somatic sensations induced by breathing air high in carbon dioxide. The results showed that symptoms were rated as more unpleasant if participants expected them to be so. Similarly, the perception of migraines, pelvic pain and back pain has been 
shown to relate to anxiety (Feuerstein et al., 1987; McGowan et al., 1998) and research indicates that both distraction and low anxiety can reduce experimentally induced pain (James and Hardardottir, 2002). Furthermore, catastrophizing cognitions, attention and fear have been shown to predict the transition from acute to chronic pain and to exacerbate its perception (Linton et al., 2000; Sullivan et al., 2001). From this perspective, symptoms are seen as a perception rather than a sensation, and psychological factors are conceptualized as moderating the intensity of the symptom experience. This model of symptom perception, however, does not challenge or explain why symptoms occur in the first place nor does it explain the type of symptoms that people perceive. Why does one person always complain of fatigue whilst another remains symptom free? Why does one person get a headache whilst another gets a sore throat? A medical explanation would explain symptom onset in terms of the presence or absence or an underlying physical problem such as a lesion, release of chemicals or the activation of neurones. However, in the same way that symptom perception appears to be influenced by psychological factors then so may symptom onset be. Furthermore, a medical perspective cannot explain why symptoms appear to cluster in time and space. If symptoms were purely a product of underlying pathology, then it could be assumed that this pathology would be relatively consistent across different cultures and throughout history. Research, however, suggests that the spread of symptoms are not so consistent and points to variation for both psychiatric and physical symptoms.

Much research in cross-cultural psychiatry and anthropology has highlighted how psychiatric symptoms vary across cultural and historical domains. Research has frequently shown that the diagnosis of schizophrenic disorders and major depression varies significantly by ethnic group (see Draguns and Tanaka-Matsumi, 2003; Littlewood and Lipsedge, 1982; Sharpley et al., 2001 for reviews). For example, the African-Caribbean population in England and the African-American population in the USA are far more likely to be diagnosed as suffering from either schizophrenia or mania than are their white counterparts. Diagnostic variation, however, may reflect more about the professionals making the diagnosis, their available diagnostic frameworks and their expectations of treatment success than the symptoms themselves. Some research, however, has also shown cultural differences in symptom presentation which may be less contaminated by dominant paradigms of diagnosis and treatment. ${ }^{1}$ For example, Minsky et al. (2003) explored diagnostic patterns in Latino, African-American and EuropeanAmerican psychiatric patients and reported that not only did the diagnoses of major depression and schizophrenic disorders vary by ethnic group but so did symptom presentation, with Latinos reporting a higher frequency of psychotic symptoms than the other groups. Similarly, a consensus statement by the International Consensus Group of Depression and Anxiety (Ballenger et al., 2001) concluded that there was wide cultural variation not only in the diagnosis and responsiveness to treatment for depression and anxiety but 
also in symptom presentation. In addition, research also reports cultural variation in less common psychiatric symptoms. For example, Amok is a taste for homicidal violence only found in South East Asia, Koro is the term for the shrinking penis syndrome experienced by men in the Far East, Witiko psychosis is a desire found in native Canadians to kill and eat one's relatives, Taijin Kyofusho is a fear of offending or hurting others through one's social behaviour or imagined physical defect which is confined to Japan, and a specific paranoia has been defined which is experienced by British West Indians (Kirmayer, 1991; Littlewood and Lipsedge, 1982). These symptoms are highly culturally specific and appear to occur within individual cultures whilst remaining unknown in others. Furthermore, psychiatric symptoms have also been shown to vary across time. For example, hysterical paralysis was commonly reported in France and Vienna in the late-19th century and yet has now practically disappeared from clinical case books (Alexander and Selesnick, 1967; Freud, 1933). In contrast, whilst anorexia and bulimia nervosa are commonly found nowadays they were rare up until about thirty years ago (Russell, 1995). A similar pattern of variation can also be found for somatic symptoms such as headaches, fatigue, constipation and back pain although research in this area is less extensive. For example, epidemiological studies indicate that whilst headache is a common symptom in the USA and western Europe, its prevalence remains much lower in China and in African and Asian populations (e.g. Stewart et al., 1996; Wang et al., 1997; Ziegler, 1990). Similarly, large surveys of primary care attenders report that those from less developed countries and from Latin America tend to report more somatic symptoms in general (Gureje et al., 1997; Piccinelli and Simon, 1997). One study explored cataract patients' reports of visual function and the extent to which they were bothered by their cataract, exploring differences by culture (Alonso et al., 1998). The results showed that after controlling for clinical and sociodemographic characteristics, patients from Canada and Barcelona reported less trouble with their vision than patients from Denmark or the USA, suggesting cultural variation in the perception of visual symptoms.

Both psychiatric and somatic symptoms therefore appear to vary by culture and across time. As a means to highlight and explain the involvement of culture in the development of symptoms, Yap (1951) defined the concept of a 'culture bound syndrome' to describe collections of symptoms which seemed only to occur within specific cultures. In line with this, researchers and clinicians have described forms of psychopathology from different times and cultures including Amok, Koro, and Witiko psychosis as described above. Although such symptoms may seem inexplicable to Western medicine, from the perspective of culture bound syndromes, it has been argued that such 'folk illnesses' or 'exotic syndromes' do make sense to the peers of those who suffer them (e.g. Littlewood and Lipsedge, 1982; Simons and Hughes, 1985). Devereux (1980a, 1980b) built upon this work and described the concept of an 'ethnic disorder'. He focused on schizophrenia, and stated that patterns of 
psychopathology within a culture are patterns of misconduct that are socially understood. He argued that certain psychological problems express the unresolved problems within any given culture and that a culture says 'don't go crazy but if you do you must behave as follows' (1980b: 42). Gordon (2000) used this perspective to analyse anorexia and bulimia nervosa and argued that 'the deviant behaviour patterns that become prevalent in a society tend to follow particular models or templates that are immediately and widely recognized by members of the culture' (p. 166). This literature on culture bound syndromes provided a theoretical framework for describing confusing collections of symptoms. It also encouraged a more relativistic approach to understanding psychological and psychiatric problems and offered a challenge to the dominant Western medical approach. Further, it emphasized the role of the cultural context to a predominantly culturally blind psychiatry movement (Littlewood and Lipsedge, 1980; Simons and Hughes, 1985). The concepts of culture bound syndromes and ethnic disorders, however, offer a description rather than an analysis of such problems. They describe the components of exotic syndromes or folk illnesses but do not provide any insights into the mechanisms behind their expression. For example, it is not clear which elements of a culture are necessary to trigger a culture bound syndrome. In addition, although they find reflection in the expression of more commonly reported somatic symptoms, they do not facilitate the prediction of what symptoms may occur when and which individuals may experience them. Further, whilst emphasising the cultural basis for symptoms, the concept of a culture bound syndrome neglects the role of the individual and cannot explain individual variability within cultures. For example, whilst some studies show cultural variation in symptomatology others show that patterns of symptoms are far more complex than can be explained along geographical or cultural lines (e.g. Gureje et al., 1997; Piccinelli and Simon, 1997; Simon et al., 1996). Why do some individuals in a particular culture experience some symptoms whilst others experience other symptoms or remain symptom free?

In summary, research on symptom perception explores the role of psychological factors in influencing the intensity of the symptom experience. However, to date this research does not explain why people develop symptoms in the first place, nor why they have the type of symptom they do. The question of symptom onset has been neglected. From a medical perspective, symptom onset could be explained in terms of underlying physical pathology. However, the vast literature on cross-cultural psychiatry and the smaller literature exploring somatic symptoms suggest that such a culturally blind approach cannot explain why both psychiatric and somatic symptoms vary across cultural and historical domains. One theoretical perspective which has emphasized this variability has drawn upon the concept of a culture bound syndrome. However, although a useful description, this approach does not explain the mechanisms behind symptom onset. In addition, with its focus on culture it neglects individual variability. In line with this, the 
present article proposes a new model to address some of the limitations of both existing symptom perception approaches and the concept of culture bound syndromes, and describes which social and psychological factors may be involved in symptom onset. The model draws upon the literatures on the etiology of diet-related symptoms to explain why symptoms arise in the first place and then to explore cultural and individual variability in symptom type. Finally, the model is applied to other common contemporary symptoms such as fatigue and headache.

\section{Deriving the model}

Over the past forty years there has been an increased prevalence of dietrelated problems and symptoms. For example, research illustrates a steady increase in the prevalence of obesity, with the rates increasing from 6 per cent of men and 8 per cent of women being obese in 1980 in the UK, to a projected 18 per cent and 24 per cent respectively by 2005 (Department of Health, 1995; Prescott-Clarke and Primatesta, 1998). Similar increases have also been documented for rates of childhood obesity (Chinn and Rona, 2001) and rates of anorexia and bulimia nervosa have also reportedly increased (Russell, 1995). Further, research also illustrates an increase in dieting behaviour and body dissatisfaction across the Western world, with estimates suggesting that up to 70 per cent of women diet and that the majority of women are dissatisfied with their weight and shape to some degree (e.g. Ogden, 2003). There has also been an apparent increase in a range of other food-related problems such as irritable bowel syndrome, food allergy and food intolerance, although details of their prevalence is hindered by problems with definition and diagnosis. In parallel there has also been a proliferation of research and literature describing and analysing food-related issues. Diet provides a focus for dieticians, nutritionists, endocrinologists, geneticists, psychiatrists, psychologists, sociologists and anthropologists that has resulted in a burgeoning numbers of books, journals and articles offering food-related coverage. As a means to develop a new model on symptom onset a subsample of the literature on diet-related symptoms was selected and analysed.

\section{Selecting the literature}

The literature on diet is vast. The methodological approach used for this article aimed to perform a textual analysis of the literature on diet using a subsample of this vast literature that reflected the larger literature in the broadest sense. Literature was therefore selected for analysis that varied across a set of domains. First, the literature was selected to reflect both primary and secondary sources. The primary sources were identified through diet-specific journals as well as general journals and illustrated original 
empirical work. The secondary sources were identified by selecting key books on the area of eating behaviour written by authors such as Mennell, Murcott and van Otterloo (1992), Orbach (1978, 1986), Grogan (1999), Conner and Armitage, (2003), Capaldi, (1996) and Szmukler, Dare and Treasure (1995), or by identifying high profile reviews. Second, the literature was selected to reflect a range of disciplines. These were Psychology (health, social, psychoanalysis), Sociology, Psychiatry, Anthropology, Epidemiology and Medicine. Third, selection was also based upon methodological approach and aimed to provide a range of methods and research designs including qualitative methods (interviews and observations), clinical cases, epidemiological studies, surveys and experimental and laboratory work. The aim of the selection procedure was to provide a wide range of literature which was deemed to reflect the literature in general. It was not intended to be either exhaustive or systematic but to enable a textual analysis of a range of source materials. Such a process of selection is in line with a historical and conceptual analysis of a range of sources.

\section{Data analysis}

Qualitative analysis usually refers to the analysis of data derived from interviews or focus groups which has been collected for the purpose of the specific study. Such data can be considered primary data, and can be analysed in a multitude of ways, drawing upon different approaches such as discourse analysis, grounded theory and interpretative phenomenological analysis, which vary in their methodology and theoretical perspectives (e.g. Smith, 2003). These approaches involve careful scrutiny of the data and the development of a coherent story which can take the form of themes, constructs or an integrated framework. There are, however, many other forms of data which are available for analysis, and in the same way that quantitative researchers often analyse secondary data that has been collected for some other purpose it is also possible to qualitatively analyse data which exists prior to any particular research study. This was the approach used for the present analysis. For example, historians analyse texts, verbal reports and historical artefacts to develop a coherent picture about the past, and literary critics analyse fiction. Those involved with the sociology of science develop their accounts on the basis of an analysis of how laboratories function, what reports have been written and how research findings become accepted truths through the generation of 'black boxes' and the recruitment of scientific support (Latour, 1987; Lynch and Woolgar, 1988). Similarly, those studying a history of ideas and the sociology of knowledge look for patterns and trends throughout a range of existing texts (e.g. Armstrong, 2003; Ogden, 2002) and researchers of mass communication analyse representations in the media (Jensen and Jankowski, 1991). Even narrative reviews involve a qualitative analysis of the existing literature. Qualitative analysis can therefore take the more 
conventional form of the analysis of transcripts of primary data. It can also involve the analysis of secondary data. The present article reflects this latter form of a qualitative analysis of the literature on diet, which was regarded as a source of secondary data. In particular, the analysis draws upon a form of textual analysis which scrutinizes text for themes and coherence and has been used for analysing media and mass communication (Larson, 1991; Silverman, 1993) and changes in representations of the individual over time (Ogden, 2002).

This textual analysis was carried out alongside a more general narrative analysis which formed the basis of a book (Ogden, 2003). The literature on diet was read and re-read to identify core themes which were apparent across empirical studies; review articles and books and were central to research generated by different methodologies using different disciplinary and theoretical perspectives. The literature was then re-read to assess that the themes adequately reflected the content of this secondary data. The themes were then cross-referenced with each other to assess any overlap and those which were considered too similar were merged into a unifying theme. Finally, exemplar illustrations were identified from the different texts to reflect each theme. These core themes were physiology, conflict, control, communication, social meanings, cognitions and emotions. This article will describe these different themes and will illustrate how they can be integrated to develop a model of diet-related symptoms. In particular, this analysis will address two key questions. First, it will explore the question 'why do symptoms arise in the first place?' which is reflected in the themes relating to physiology, conflict, control and communication. Second, it will explore the question 'what type of symptom is experienced?' which is reflected in the themes relating to social meanings, cognitions and emotions. Further, the article will explore the extent to which the new model can be used to explain the onset of other symptoms, which, like diet-related symptoms, seem to be located in a specific time and space.

\section{Why do symptoms arise in the first place?}

Why do some people have symptoms whilst others remain symptom free? Why are symptoms more likely to be experienced during some periods of the lifespan such as adolescence and retirement whilst symptoms are rare in others?

\section{Physiology}

From a medical perspective, symptoms arise due to an underlying change in physiology such as release of chemicals, a lesion or a virus. The analysis of diet-related symptoms also suggests a role for physiology. For example, physiological processes have been described in relation to hunger, food choice and food preferences (Blundell et al., 1989; Denton, 1982; Desor, Maller and Turner, 1973; Geldard, 1972), work has illustrated how 
caffeine, carbohydrates and chocolate can change cognitions and mood (Lieberman et al., 1990; Tuomisto et al., 1999) and stress-induced eating has been explained in terms of arousal and or cortisol (Epel et al., 2000). Further, research has also emphasized biological factors in the etiology of eatingrelated problems such as obesity (Allison et al., 1996; Stunkard et al., 1990) and eating disorders (Kendler et al., 1991; Treasure and Holland, 1989, 1995). Such an analysis also finds reflection in work on embodiment and the visceral nature of symptoms and illness (Haraway, 1991; Radley, 1984; Shilling, 1993). However, whereas a physiological analysis would conceptualize physiology as the driver for symptom experience, an embodied approach would suggest a dynamic between the body and the symptoms arising from it. Diet-related symptoms would therefore seem to show a role for physiology.

An individual, however, does not live in isolation but is located within a social world and both influences and is influenced by their context (Giddens, 1991). This interface between the individual and their social world is not unproblematic and can create tensions as the individual negotiates where they end and where the social context starts. The literature on diet related symptoms suggests that this tension is characterized by issues of conflict and control.

\section{Conflict}

The literature describes how food generates and is central to a range of conflicts. Some foods are particularly marketed as epitomizing the conflict between pleasure and guilt. Slogans describe 'naughty but nice', 'forbidden fruit' and 'sins of the flesh', suggesting that foods can be both pleasurable and guilt-ridden objects. Similarly, Chernin (1992) describes both her need for food and her subsequent self-loathing, and Levine (1997) describes her relationship to food using words such as 'shame', 'frantic' and 'love'. Food also establishes a conflict between eating and denial, and Charles and Kerr $(1986,1987)$ concluded from their study of young mothers in England that these women are motivated both by the need to provide food for their family and by the need to deny themselves as a means to stay thin and attractive. Likewise, Lawrence (1984) describes how her patients 'take control of food whilst simultaneously denying themselves the pleasure of it' (p. 31) and Orbach (1986) states that 'women have occupied this dual role of feeding others while needing to deny themselves' (p. 60). Much has also been written about the conflicts surrounding gender and the changing role of women. As Orbach states, 'women have occupied this dual role of feeding others while needing to deny themselves ... women must hold back their desires for the cakes they bake for others and satisfy themselves with a brine canned tuna salad with dietetic trimmings' (1986: 60). In parallel, Gordon (2000) argues that conflicts around gender are central to the development of eating disorders and that it is the multiplicity of role demands, many of which seem to conflict with one another, which make the contemporary situation so difficult for women' (p. 111). In particular, he points to the 
contrasting roles of career women and motherhood, traditional and nontraditional roles which have also been explored in more empirical research (e.g. Klingenspor, 1994). Research also highlights a role for conflicts associated with identity, particularly relating to identities of dependent versus independent and adult versus child. For example, Lawrence (1984) describes how her patients seem to suffer an 'identity crisis' at the time of onset of an eating disorder, and suggests that this is why onset is often at a time of transition when an individual's identity is under particular threat. Therefore, as the individual interfaces with their social world, tension arises through the conflicts created by the contradictory expectations and roles offered by society.

\section{Control}

The literature on diet-related symptoms suggests that this tension is also characterized by issues of control. At times this has been described within the context of the family. For example, Birch and colleagues have carried out a series of studies examining whether food restriction by parents reduces or increases the preference for the restricted food, and have concluded that 'child feeding strategies that restrict children's access to snack foods actually make the restricted foods more attractive' (Birch, 1999:52; Fisher and Birch, 1999; Fisher at al., 2000). Research has also highlighted how issues of control arise as an individual interfaces with their wider social world. For example, Constance Lytton (1914) was a suffragette who was imprisoned following a public protest. She subsequently went on a hunger strike and stated that 'our fast is against the government and we shall fight them with our lives not hurting anyone else' (p. 260) and describes how not eating was a means to regain social control. In line with this, Gordon (2000) argued that 'historically the hunger strike has been employed by the socially oppressed as a means of embarrassing or humiliating those in control and ultima-tely extracting concessions from them' (p. 194). In parallel, Orbach (1986) described anorexia as a 'hunger strike' and Gordon analysed the hunger artists of the 19th century, stating that 'their food refusal was a sheer act of will and self control for its own sake' (2000: 195). Therefore, both under- and overeating are analysed in terms of control with the focus on both individual statements of self-control in the context of the family and social statements of power. It would seem therefore that tensions may be created as the individual interacts with others, raising issues of control as the boundaries of responsibility, blame and accountability become blurred.

\section{Communication}

Thus, an individual with their physiology is located within a complex and sometimes contradictory social context which can generate tensions through issues of conflict and control. These tensions could simply be absorbed or experienced by the individual. However, much research suggests that tension needs to be communicated and that symptoms are often a form 
of this communication. This is particularly apparent within the diet-related literature in which symptoms are conceptualized as a communicative act. For example, Dare and Crowther (1995a, 1995b) argue that food avoidance and the resulting weight loss has two meanings. First, it says 'This is an area in which I am in control', and second, it says 'I am only a little child, I cannot live by myself, I have to be looked after' (Dare and Crowther, 1995a: 135). Similarly, family systems theory also describes symptoms as communicative acts (Eisler, 1993,1995) and suggests that a symptom appears when a person 'is in an impossible situation and is trying to break out of it' (Haley, 1973: 44). Further, psychoanalytic psychotherapy for eating disorders describes the development of a focal hypothesis by the therapist, involving an analysis of 'the use the patient makes of the symptoms in current personal relations' (Dare and Crowther, 1995a: 298). In addition to this, clinical literature suggests food is also used as a form of communication within day-to-day social relationships. For example, research indicates that food is used to communicate love within the family, with Charles and Kerr (1987) concluding that healthy and tasty foods are signs of family love and the determination to please and satisfy the family, and Lawrence stating that 'taking care over the preparation of food is an act of love' (1984:29). Furthermore, studies suggest that food is used as part of rite of passage ceremonies to communicate the onset of puberty and sexuality (Jacobs, 1958; Marshall, 1976). Fiddes (1990) argues that eating meat is a means of communicating our cultured status and of demarcating us from the natural world, and Mennell et al. (1992) have argued that food is a sign of plenty and wealth. Likewise, food plays a central role in communicating a celebration and the need for indulgence (Bordo, 1990).

Accordingly, the tensions generated as an individual interfaces with their social world require some form of outlet or communication, and the model proposed in this article suggests that they are communicated through symptoms. Such tension therefore forms the prerequisite stage for symptom onset and illustrates the necessary components for symptom origination. This analysis finds reflection in a psychoanalytic understanding of psychosomatic illness (e.g. Eisler, 1993,1995) and is similar to work on somatization whereby symptoms are conceptualized as the unconscious expression of underlying psychological states (e.g. Minuchin et al., 1978). The present model suggests that whilst for some, symptoms may well reflect a process of communication which occurs at the unconscious level, for others the expression of tension may illustrate a more conscious and cognitive process with issues of both conflict and control occurring at both a conscious cognitive and a preconscious level. Further, whilst such psychosomatic research has focused on the symptomatic expression of specific clinical disorders such as anxiety and depression (e.g. Feder et al., 2001; Henningsen et al. 2003; Katon and Walker, 1998), the current model suggests that symptoms may originate from any psychological state characterized by tensions arising from issues of conflict and control. ${ }^{2}$ 


\section{What type of symptom is experienced?}

The proposed model suggests that tensions generated as an individual influences and is influenced by their social world need to find an outlet and that symptoms can be conceptualized as a form of communication. But what determines the type of symptom experienced? Why are some symptoms common within one culture whilst inexplicable to others? Why do some people get headaches whilst others get stomach pain? What factors translate the necessary prerequisites of symptom origination into symptom onset? Symptoms show cultural variation and this has been analysed from the perspective of culture bound syndromes (Devreux, 1980a, 1980b; Littlewood and Lipsedge, 1982; Yap, 1951). The present model suggests that tensions are communicated through symptoms that are offered up by a series of social meanings. In particular, it is argued that such meanings offer a socially sanctioned pathway which sanctions the expression of tension in culturally meaningful ways.

\section{Social meanings}

This socially sanctioned pathway is illustrated by the social meanings surrounding food and weight. For example, the sociological and anthropological literature emphasizes the meanings people attach to food which are specific to both culture and time. For example, food is associated with sexuality and advertisements reflect and encourage this association in their attempts to sell foods such as ice cream, chocolate bars and other 'forbidden fruits' (Mennell et al., 1992). Likewise, rite of passage ceremonies often use food to symbolize the onset of puberty and to reflect the burgeoning of sexuality, and celebratory meals are often used as a precursor to sexual encounters (Fiddes, 1990; Marshall, 1976). Food is also embedded with meanings of guilt (MacDiarmid and Hetherington, 1995) and some of the psychoanalytic literature describes how food and eating is associated with self-loathing (Chernin, 1992). In addition, some foods are conceptualized as a treat and pleasurable and as central to demonstrations of love and caring. For example, Lawrence argues that 'Food is the medium through which women demonstrate our love and concern for our children, lovers, husbands and friends' (1984: 29). The family is also described in terms of the meanings attributed to food. For example, research indicates that portion sizes often reflect the power dynamics within a family, with the men eating first, being given more food and food of a higher quality than either women or children (Charles and Kerr, 1986, 1987; Delphy, 1979; Millett, 1969; Murcott, 1983). In addition, food and eating have been read as expressing issues of control, both in terms of the lack of control associated with bingeing and the degree of self-control illustrated by food avoidance and abstinence (Gordon, 2000). There are also many social meanings associated with body size. For example, quantitative research has highlighted how people consistently associate obesity and overweight with characteristics such as being unattractive, 
lacking self-discipline, lazy, unpopular, stupid and unsuccessful (Lerner and Gellert, 1969; Staffieri, 1967; Tiggemann and Rothblum, 1988; Wadden and Stunkard, 1985). Further, qualitative and psychoanalytic work suggests that thinness is associated with control, freedom and success. For example, Bordo argued that "the slender body codes the tantalising ideal of a well managed self in which all is in order despite the contradictions of the consumer culture' (1990: 97). Food and weight are therefore currently embedded with a range of social meanings. Such meanings offer up a socially sanctioned pathway for the expression of tensions. For example, if tensions relate to feeling out of control then diet related symptoms are an effective forum for expression. Similarly, if conflicts resulting sexuality, power or guilt are the issues then food avoidance or overeating could be useful symptoms to communicate such problems. This socially sanctioned pathway offers a culturally meaningful forum for communication. Further, such meanings are themselves located within contemporary Western culture, and as these meanings have become increasingly common then so have the resulting diet related symptoms.

But although symptoms show cultural variation they also show individual variation, and members of a particular culture do not inevitably experience particular symptoms. Why does one person within a culture get a headache whilst another has stomach pain? Not everyone in a contemporary culture experiences the same symptoms and therefore not everyone communicates issues of conflict and control in an identical way. Rather, each individual appraises the socially sanctioned pathway in the context of their own cognitions and emotions.

\section{Cognitions and emotions}

In terms of diet-related symptoms, if an individual appraises the socially sanctioned pathway offering diet-related symptoms as personally relevant, then the pathway is followed and issues of conflict and control will be expressed as symptoms relating to food and weight. If assessed as irrelevant, then an individual may follow an alternative pathway for communication. This process of appraisal finds reflection in the transactional theory of stress (Lazarus and Folkman, 1987) in which the experience of stress is conceptualized as a result of the appraisal of the both the external stressor and the individual's own coping mechanisms. Similarly, the process of coping is considered to consist of the regulation of both the external stressor and the internal emotional response (Cohen and Lazarus, 1979). To date, there are relatively few studies exploring the cognitive and emotional precursors to the onset of diet related symptoms. However, it is hypothesized that those who develop diet-related symptoms hold the kind of cognitions which make the socially sanctioned pathway seem personally relevant. For example, before symptom onset, people prone to diet-related symptoms may believe that food avoidance or overeating reflect aspects of control, that being thin is a desirable state and that people who show 
diet-related symptoms have been subjected to uncontrollable stressors. Similarly, they may show emotional responses which may also render the socially sanctioned pathway relevant, and feel that those with dietrelated symptoms deserve sympathy and should not be stigmatized. In contrast it is hypothesized that those who show a different set of cognitions and emotions would appraise the socially sanctioned pathway as irrelevant, and that food and weight-related problems would not be their symptoms. Alternative symptoms may function more effectively. Thus the translation of the tension into symptoms requires both a socially sanctioned pathway and an appraisal of this pathway as personally relevant.

In summary, an analysis of the literature on diet generated a series of themes that have been integrated into a new model which describes three stages of symptom onset. First, it is argued that tensions relating to issues of conflict and control arise as an individual interfaces with their social world and it is suggested that these tensions require communication and form the necessary prerequisites for symptom onset. Second, it is suggested that symptoms are embedded with culturally specific meanings which offer up a socially sanctioned pathway as a forum for communication. Third, this pathway is appraised by the individual in the context of their own cognitions and emotions and if appraised as personally relevant, symptoms will result which are both culturally and personally meaningful. This model, with a socially sanctioned pathway appraised by the individual at its core, is derived from an analysis of the literature on diet but is also offered as a means to understand, explain and possibly predict the onset of other more common symptoms. Such symptoms will be experienced as 'real', 'physical', and 'visceral' but will be both socially and temporally located in a way that finds reflection in an embodied experience (Haraway, 1991; Radley, 1984; Shilling, 1993). This model is illustrated in Figure 1.

\section{The socially sanctioned pathway and the emergence of other symptoms}

This model of diet-related symptoms suggests that the socially sanctioned pathway offered by the meanings of food and weight generates a forum through which tensions of conflict and control can be expressed. This approach finds reflection in research exploring the social meanings of obesity and eating disorders and how such problems are socially and temporally located (Evans et al., 2003; Gordon, 2000; Warin, 2004). Not everyone, however, follows this pathway. Problems of diet and weight may be on the increase but they are by no means universal. This is in part explained by the appraisal component of the model and the need for the pathway to be of personal relevance. But perhaps it can also be explained by the existence of other co-existing socially sanctioned pathways. Food and weight are one pathway and a commonly used one, but other pathways may exist. As such, the model of diet-related symptoms described in this article may not only help to 


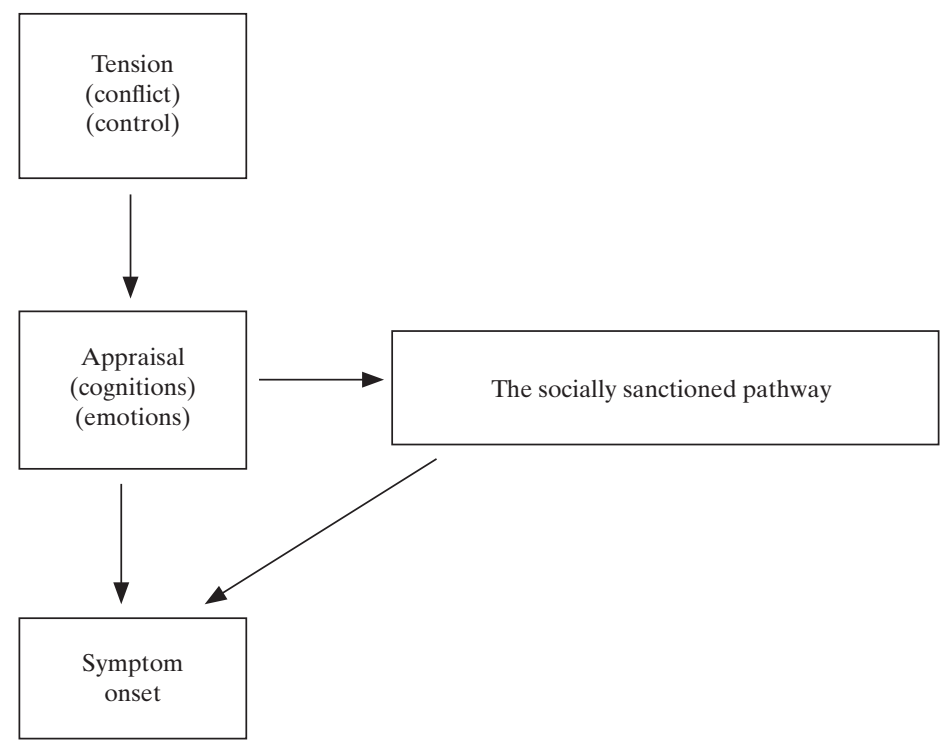

Figure 1 The socially sanctioned pathway model of symptoms

explain diet-related symptoms, but may also generalize as an explanatory framework to provide a sense of the mechanisms behind culture bound syndromes and ethnic disorders. For example, the meanings of aggression, control and authority held within certain cultures may offer the socially sanctioned pathway for syndromes such as Amok, and meanings surrounding sexuality and potency may offer the pathway for Koro. Further, the model may also help to explain other 'medically unexplained symptoms' which to date have been measured, counted and described, but whose etiology has remained a mystery (e.g. Henningsen et al., 2003; Isaac et al.,1995; Nimnuan et al., 2001). For example, the meanings of achievement, productivity and, conversely, lethargy may offer a socially sanctioned pathway resulting in the increasingly common symptoms of fatigue, depression and stress. Similarly, the meanings of pain as a legitimate ticket of entry to medicine may offer a pathway resulting in symptoms such as repetitive strain injury, chronic pain, headaches and back ache. These socially sanctioned pathways are offered by a set of social meanings as possible outlets for the tensions around control and conflict generated as the individual locates themselves within their social world. If appraised as relevant, then the pathway may be operationalized and the appropriate symptoms experienced. If appraised as irrelevant, then alternative outlets may be sought.

Predictions could therefore be made as to when, where and by whom symptoms would be experienced. For example, the onset of tiredness would require three key factors: the individual to experience tensions generated by issues of control and conflict, a contemporary socially sanctioned pathway which offers tiredness as a solution, and a cognitive and emotional setting 
which appraises this pathway as relevant and meaningful. Similarly, the onset of headaches would also require tension, a socially sanctioned pathway which offers headaches as the solution and a cognitive and emotional setting that appraises this pathway as relevant. If either the pathway is absent or the appraisal process renders this pathway irrelevant, then the tension may find an alternative outlet. Such predictions could be empirically tested and future research could aim to explore whether symptom onset can be predicted in this way.

\section{Conclusion}

Research highlights a role for psychological factors in the perception of symptoms, but the issue of symptom onset remains neglected. From a medical perspective, symptom onset could be explained in terms of underlying changes in physiology. However, such an analysis cannot explain why symptoms vary across both culture and time. As a means of understanding such cultural variation, researchers have described culture bound syndromes or ethnic disorders, but these constructs do not provide any real insights into the mechanisms behind the production of such problems and nor can they explain individual variability within specific cultures. Using the literature on diet, the present article has identified a series of themes common across disciplines and methodologies which have been integrated to derive a model to explain why diet-related symptoms are on the increase in the Western world. It is argued that this model may also provide insights into the mechanisms behind other symptoms. As individuals interface with their social world, tensions are generated, through issues of conflict and control, which require a forum for communication. In terms of diet-related symptoms, the contemporary meanings of food and weight offer a socially sanctioned pathway that is currently personally relevant for large numbers of people. This results in diet-related symptoms ranging from eating disorders and obesity to food intolerance. But not everyone experiences diet-related symptoms and not all issues of conflict and control are expressed in this way. Some may identify with alternative pathways generated by other meanings and producing other symptoms. Some may respond more to pathways that lead to exotic folk illnesses, whilst others may find pathways resulting in medically unexplained symptoms to be more personally relevant. ${ }^{3}$ From this perspective, symptom onset may no longer be conceptualized as an inevitable consequence of underlying physiological changes but as a result of tension, a socially sanctioned pathway and appraisal. Not only may symptom perception involve a range of psychological factors but so may symptom onset, and the constructs presented in this new model could be used to explain and even predict which symptoms will emerge when and for whom and within which time and space. 


\section{Notes}

1. It is important to differentiate between the status of data based upon symptom perception, symptom presentation or symptom diagnosis. As percepts, symptoms are inevitably located within the individual's psychological and social world. However, once presented they have become a part of the medical domain as the patient has made the decision to offer up their symptoms for examination. Symptom presentation therefore reflects percepts which are being communicated. But symptoms that have been diagnosed and labelled by a health professional reflect an individual's own symptom experience which has been transformed into a diagnosis in the context of a health professional's diagnostic framework. Variation in such symptoms may reflect as much about changes in health professionals' beliefs and expectations as those of the individual. Symptoms per se illustrate an individual's construction of their experience, but the progression from perception, to presentation through to diagnosis reflects an increasingly socially constructed version of this experience as it becomes increasingly the property of the dominant health paradigm. (In fact even the existence of diagnoses will feedback and influence all levels of the symptom experience.)

2. The current article aims to provide a model which could facilitate an understanding of the origins of symptoms. To date, research on symptoms is clearly divided into somatic and psychiatric symptoms which occupy different disciplinary frameworks and are researched using different tools and by different researchers. It is possible that the processes involved in the origination of symptoms, regardless of whether they are conceptualized as somatic or psychiatric (itself an arbitrary distinction), may be comparable, and that the model proposed in this article could be relevant to both. Due to the absence of any data this suggestion remains purely speculative.

3. The process of communication and the appraisal of a socially sanctioned pathway raise the issue of choice and conscious control. Early psychological theorizing clearly differentiated between the conscious and unconscious, with choice being seen as a result of conscious processing which may or may not have been influenced by the unconscious. More recently, this divide between the conscious and unconscious has become blurred and a more dynamic, fluid model has been adopted. The present article adopts this latter theoretical stance and suggests that symptoms are the result of the desire to communicate, combined with a complex appraisal of social meanings and the individual's own cognitions and emotions which are processed at both the conscious and unconscious levels. To this extent, the individual 'chooses' which socially sanctioned pathway to adopt and which symptom to experience. But this is not to attribute blame, responsibility or control to the individual; just to illustrate symptoms as the end product of a series of interpretations and assimilations.

\section{References}

Alexander, F.G. and Selesnick, S.T. (1967). The history of psychiatry: An evaluation of psychiatric thought and practice from prehistoric times to the present. London: George Allen and Unwin.

Allison, D.B., Kaprio, J., Korkeila, M., Neale, M.C. and Hayakawa, K. (1996). The heritability of body mass index among an international sample of monozygotic twins reared apart. International Journal of Obesity, 20, 501-6. 
Alonso, J., Black, C., Norregaard, J.C., Dunn, E., Andersen, T.F., Esallargues, M., Bernth-Petersen, P. and Andersen, GF. (1998). Cross cultural differences in the reporting of global functional capacity: An example in cataract patients. Medical Care, 36, 868-78.

Armstrong, D. (2003). A new history of identity. Basingstoke: Palgrave.

Ballenger, J.C., Davidson, J.R., Lecrubier Y., Nutt, D.J., Kirmayer, L.J., Lepine, J.P., Lin, K.M., Tajima, O. and Ono, Y. (2001). Consensus statement on transcultural issues in depression and anxiety from the International Consensus Group on Depression and Anxiety. Journal of Clinical Psychiatry, 62 (Suppl 13), 47-55.

Birch, L.L. (1999). Development of food preferences. Annual Review of Nutrition, $19,41-62$

Blundell, J.E., Hill, A.J. and Lawton, C.L. (1989). Neurochemical factors involved in normal and abnormal eating in humans. In R. Shepherd (Ed.), Handbook of the psychophysiology of human eating, pp 85-112. London: Wiley.

Bordo, S. (1990). Reading the slender body. In M. Jacobus, E.F. Keller and S. Shuttleworth (Eds.), Body/Politics: Women and the discourses of science. New York: Routledge.

Capaldi, E., Ed. (1996). Why we eat what we eat. The psychology of eating. Washington: Amercan Psychological Association.

Charles, N. and Kerr, M. (1986). Eating properly: The family and state benefit. Sociology, 20(3), 412-29.

Charles, N. and Kerr, M. (1987). Just the way it is: Gender and age differences in family food consumption. In J. Brannen and G. Wilson (Eds.), Give and take in families: Studies in resource distribution. London: Allen and Unwin.

Chernin, K. (1992). Confessions of an eater. In D.W. Curtin and L.M. Heldke (Eds.), Cooking, eating, thinking: Transformative philosophies of food. Bloomington, IN: Indiana University Press.

Chinn, S. and Rona, R.J. (2001). Prevalence and trends in overweight and obesity in three cross sectional studies of British children, 1974-94. British Medical Journal, 322, 24-6.

Cohen, F. and Lazarus, R.S. (1979). Coping with the stresses of illness. In G.C. Stone, F. Cohen and N.E. Adler (Eds.), Health psychology: A handbook, pp 217-54. San Francisco, CA: Jossey-Bass.

Conner, M. and Armitage, C. (2003). The social psychology of diet. London: McGraw-Hill.

Dare, C. and Crowther, C. (1995a). Psychodynamic models of eating disorders. In G. Szmukler, C. Dare and J. Treasure (Eds.), Handbook of eating disorders: Theory, treatment and research, pp. 125-139. London: Wiley.

Dare, C. and Crowther, C. (1995b). Living dangerously: Psychoanalytic psychotherapy of anorexia nervosa. In G. Szmukler, C. Dare and J. Treasure (Eds.), Handbook of eating disorders: Theory, treatment and research, pp. 293-307. London: Wiley.

Delphy, C. (1979). Sharing the same table: Consumption and the family. In C. Harris (Ed.), The sociology of the family: New directions for Britain. Sociological Review Monograph 28. Keele: University of Keele Press.

Denton, D. (1982). The hunger for salt. Berlin: Springer Verlag.

Department of Health (1995). Obesity: Reversing an increasing problem of obesity in England. A report from the Nutrition and Physical activity task forces. London: HMSO. 
Desor, J.A., Maller, O. and Turner, R.E. (1973). Taste and acceptance of sugars by human infants. Journal of Comparative and Physiological Psychology, 84, 496-501.

Devereux, G. (1980a). Normal and abnormal. In Basic problems of ethnopsychiatry, pp. 3-71. Chicago, IL: University of Chicago Press.

Devereux, G. (1980b). Schizophrenia: An ethnic psychosis, or schizophrenia without tears. In Basic problems of ethno-psychiatry, pp. 214-36. Chicago, IL: University of Chicago Press.

Draguns, J.G. and Tanaka-Matsumi, J. (2003). Assessment of psychopathology across and within cultures: issues and findings. Behaviour Research and Therapy, 41, 755-76.

Eisler, I. (1993). Families, family therapy and psychosomatic illness. In S Moorey and M Hodes (Eds.), Psychological treatments in human disease and illness. London: Gaskill.

Eisler, I. (1995). Family models of eating disorders. In G. Szmukler, C. Dare and J. Treasure (Eds.), Handbook of eating disorders: Theory, treatment and research, pp. 293-307. London: Wiley.

Epel, E.S., McEwen, B., Seeman, T., Matthews, K., Castellazzo, G., Brownell, K.D., Bell, J. and Ickovics, J.R. (2000). Stress and body shape: Stress-induced cortisol secretion is consistently greater among women with central fat. Psychosom Med, 62(5), 623-32.

Evans, J., Evans, B. and Rich, E. (2003). 'The only problem is they will like their chips'. Education and the discursive production of ill-health. Pedagogy, Culture and Society, 11(2), 215-41.

Feder, A., Olfson, M., Gameroff, M., Fuentes, M., Shea, S., Lantigua, R.A. and Weissman, M.M. (2001). Medically unexplained symptoms in an urban general medical practice. Psychosomatics, 42, 261-8.

Feuerstein, M., Carter, R.L. and Papciak, A.S. (1987). A prospective analysis of stress and fatigue in recurrent low back pain. Pain, 31, 333-44.

Fiddes, N. (1990). Meat: A natural symbol. London: Routledge.

Fisher, J.O. and Birch, L.L. (1999). Restricting access to a palatable food affects children's behavioral response, food selection and intake. American Journal of Clinical Nutrition, 69, 1264-72.

Fisher, J.O., Birch, L.L., Smiciklas-Wright, H. and Piocciano, M.F. (2000). Breastfeeding through the first year predicts maternal control in feeding and subsequent toddler energy intakes. Journal of the American Diet Association, 100, 641-6.

Freud S (1933) New Introductory Lectures on Psychoanalysis. First English translation, Tr. W J H Sprott. London and New York.

Geldard, F.A. (1972). The human senses. New York: Wiley

Giddens, A. (1991). Modernity and self identity: Self and society in the later modern age. Cambridge: Polity Press.

Gordon, R.A. (2000). Eating disorders: Anatomy of a social epidemic. Second edition. Oxford: Blackwell.

Grogan, S. (1999) Body image: Understanding body dissatisfaction in men, women and children. London: Routledge.

Gureje, O., Simon, G.E., Ustun, T.B. and Goldberg, D.P. (1997). Somatisation in cross cultural perspective: A World Health Organisation study in primary care. American Journal of Psychiatry, 154, 989-995. 
Haley, J. (1973). Uncommon therapy: The psychiatric techniques of Milton H. Erickson, M.D. New York: W.W. Norton.

Haraway, D. (1991). Simians, cyborgs and women: The reinvention of nature. London: Free Association books.

Henningsen, P., Zimmermann, T. and Sattel, H. (2003). Medically unexplained symptoms, anxiety and depression: A meta analytic review. Psychosomatic Medicine, 65, 528-33.

Isaac, M., Janca, A., Burke, K.C., Costa, E., Silva, J.A., Acuda, S.W., Altamura, A.C., Burke, J., Chandrashekar, C.R., Miranda, C.T. and Tacchini, G. (1995). Medically unexplained somatic symptoms in different cultures. A preliminary report from phase 1 of the World Health Organisation International Study of Somatoform Disorders. Psychotherapy and Psychosomatics, 64, 88-93.

Jacobs, A.H. (1958). Masai age-groups and some functional tasks. East African Institute of Social Research Conference Proceedings, Makerere.

James, J.E. and Hardardottir, D. (2002). Influence of attention focus and trait anxiety on tolerance of acute pain. British Journal of Health Psychology, 7, 149-62.

Jensen, K.B. and Jankowski, N.W., Eds. (1991). A handbook of qualitative methods for mass communication research. London: Routledge.

Katon, W.J. and Walker, E.A. (1998). Medically unexplained symptoms in Primary Care. Journal of Clinical Psychiatry, 59(suppl 20), 15-21.

Kendler, K.S., Maclean, C., Neale, M., Kessler, R., Heath, A. and Eaves, L. (1991). The genetic epidemiology of bulimia nervosa. American Journal of Psychiatry, 148, 1627-37.

Kirmayer, L.J. (1991). The place of culture in psychiatric nosology: Taijin Kyofusho and DSM 111 R. Journal of Nervous Mental Disorders, 179, 19-28.

Klingenspor, B. (1994). Gender identity and bulimic eating behaviour. Sex Roles, 31, 407-31.

Larson, P. (1991). Textual analysis of fictional media content. In. K.B. Jensen and N.W. Jankowski (Eds.), A handbook of qualitative methods for mass communication research. London: Routledge.

Latour, B. (1987). Science in action. Milton Keynes: Open University Press.

Lawrence, M. (1984) The anorexic experience. London: The Women's Press.

Lazarus, R.S. and Folkman, S. (1987). Transactional theory and research on emotions and coping. European Journal of Personality, 1, 141-70.

Lerner, R.M. and Gellert, E. (1969). Body build identification, preference and aversion in children. Developmental Psychology, 1, 456-62.

Levine, M.J. (1997). I wish I were thin; I wish I were fat. New York: Fireside Books.

Lieberman, H.R., Gabrieli, J.D.E., Nader, T. and Wurtman, R.J. (1990). Changes in mood, performance and memory induced by moderate doses of caffeine.

Linton, S.J., Buer, N., Vlaeyen, J. and Hellising, A. (2000). Are fear-avoidance beliefs related to the inception of an episode of back pain? A prospective study. Psychology and Health, 14, 1051-9.

Littlewood, R. and Lipsedge, R. (1982). Aliens and alienists: Ethnic minorities and psychiatry. Middlesex: Penguin.

Lynch, M. and Woolgar, S. (1988). Introduction: Sociological orientations to representational practice in science. In M Lynch and S Woolgar (Eds.), Representation in scientific practice. Amsterdam: Kluwer Academic.

Lytton, C. (1914). Prisons and prisoners. London: Heinemann. 
MacDiarmid, J.I., Hetherington, M.M. (1995). Mood modulation by food: An exploration of affect and cravings in 'chocolate addicts'. British Journal of Clinical Psychology, 34, 129-38.

McGowan, L.P.A., Clarke-Carter, D.D. and Pitts, M.K. (1998). Chronic pelvic pain: A meta-analytic review. Psychology and Health, 13, 937-51.

Marshall, L. (1976). The Kung of Nyae Nyae. Cambridge, MA: Harvard University Press.

Mennell, S., Murcott, A. and van Otterloo, A.H. (1992). The sociology of food: Eating, diet and culture. London: Sage.

Millett, K. (1969). Sexual politics. London: Virago Press.

Minsky, S., Vega, W., Miskimen, T., Gara, M. and Escobar, J. (2003). Diagnostic patterns in Latino, African American and European American Psychiatric patients. Archives of General Psychiatry, 60, 637-44.

Minuchin, S., Rosman, B.L., and Baker, L. (1978). The anorectic family. In Psychosomatic families: Anorexia nervosa in context, pp. 51-73. London: Harvard University Press.

Murcott, A. (1983). Women's place: Cookbooks' images of technique and technology in the British kitchen. Women's Studies International Forum, 6(1), 33-9.

Nimnuan, C., Hotopf, M., and Wessely, S. (2001). Medically unexplained symptoms: An epidemiological study in seven specialities. Journal of Psychosomatic Research, 51, 361-7.

Ogden, J. (2002). Health and the construction of the individual. London: Routledge.

Ogden, J. (2003). The psychology of eating: From healthy to disordered behaviour. Oxford: Blackwell.

Orbach, S. (1978). Fat is a feminist issue. How to lose weight permanently - without dieting. London: Arrow Books.

Orbach, S. (1986; 1993). Hunger strike: The anorectic's struggle as a metaphor for our age. London: Faber and Faber.

Pennebaker, J.W. (1983). Accuracy of symptom perception. In A. Baum, S.E. Taylor and J. Singer (Eds.), Handbook of Psychology and Health, Volume 4. Hillsdale, NJ: Erlbaum.

Piccinelli, M. and Simon, G. (1997). Gender and cross-cultural differences in somatic symptoms associated with emotional distress. An international study in primary care. Psychological Medicine, 27, 433-44.

Prescott-Clarke P. and Primatesta P. (1998). Health survey for England 1996. London: HMSO.

Radley, A. (1984). The embodiment of social relation in coronary heart disease. Social Science and Medicine, 19, 1227-34.

Russell, G.F.M. (1995). Anorexia nervosa through time. In G. Szmukler, C. Dare and J. Treasure (Eds.), Handbook of eating disorders: Theory, treatment and research, Chapter 1, pp. 5-17. London: Wiley.

Sharpley, M., Hutchinson, G., McKensie, K., and Murray, R.M. (2001). Understanding the excess of psychosis among the African Caribbean population in England. Review of current hypotheses. British Journal of Psychiatry, Suppl. $40,60-8$.

Shilling, C. (1993). The body and social theory. London: Sage.

Silverman, D. (1993). Interpreting qualitative data. London: Sage.

Simon, G., Gater, R., Kisley, S. and Piccinelli, M. (1996). Somatic Symptoms of distress: An international primary care study. Psychosomatic Medicine, 58, 481-8. 
Simons, R.C. and Hughes, C.C., Eds. (1985) The culture bound syndromes: Folk illnesses of psychiatric and anthropological interest. Dordrecht: D Reidel Publishing Company.

Smith, J.A. (2003). Qualitative psychology. London: Sage.

Staffieri, J.F. (1967). A study of social stereotype of body image in children. Journal of Personality and Social Psychology, 7, 101-4.

Stegen, K., Van Diest, I., Van De Woestijne, K.P. and Van Den Berch, O. (2000) Negative affectivity and bodily sensations induced by $5.5 \% \mathrm{CO}_{2}$ enriched air inhalation: Is there a bias to interpret bodily sensations negatively in persons with negative affect? Psychology and Health, 15, 513-25.

Stewart, W.F., Lipton, R.B. and LIberman, J. (1996). Variation in migraine prevalence by race. Neurology, 47, 52-9.

Stunkard, A.J., Harris, J.R. Pedersen, N.L. and McClearn, G.E. (1990) A separated twin study of body mass index. New England Journal of Medicine, 322, 1483-7.

Sullivan, M.J.L., Thorn, B., Haythornthwaite, J.A. et al. (2001). Theoretical perspectives on the relation between catastrophising and pain. Clinical Journal of Pain, 17, 53-61.

Szmukler, G., Dare, C. and Treasure, J., Eds. (1995). Handbook of eating disorders: Theory, treatment and research. London: Wiley

Tiggemann, M. and Rothblum, Eds. (1988). Gender differences in social consequences of perceived overweight in the United States and Australia. Sex Roles, 18, 75-86.

Treasure, J.L. and Holland, A.J. (1989). Genetic vulnerability to eating disorders: Evidence from twin and family studies. In H. Remschmidt and M.H. Schmidt (Eds.), Anorexia nervosa, pp. 59-68. Toronto: Hogrefe \& Huber.

Treasure, J. and Holland, A. (1995). Genetic factors in eating disorders. In G. Szmukler, C. Dare and J. Treasure (Eds.), Handbook of eating disorders: Theory, treatment and research, pp. 65-81. London: Wiley.

Tuomisto, T., Hetherington, M.M., Morris, M.F., Tuomisto, M.T., Turjanmaa, V. and Lappalainen, R. (1999). Psychological and physiological characteristics of sweet food addiction. International Journal of Eating Disorders, 25(2), 169-75.

Wadden, T.A. and Stunkard, A.J. (1985). Social and psychological consequences of obesity. Annals of Internal Medicine, 103, 1062-7.

Wang, S.J., Liu, H.C., Fuh, J.L., Liu, C.Y., Lin, K.P., Chen, H.M., Lin, C.H., Wang, P.N., Hsu, L.C., Wang, H.C. and Lin, K.N. (1997). Prevalence of headaches in a Chinese elderly population in Kinmen: Age and gender effect and cross-cultural comparisons. Neurology, 49, 195-200.

Warin, M. (2004). Primitivising anorexia: The irresistible spectacle of not eating. The Australian Journal of Anthropology, 15, 95-104.

Yap, P.M. (1951). Mental disease peculiar to certain cultures: A survey of comparative psychiatry. Journal of Mental Science, 97, 313-27.

Ziegler, D.K. (1990). Headache. Public health problem. Neurol Clin, 8, 781-91.

\section{Author Biography}

JANE OGDEN is Professor in Health Psychology at the University of Surrey. Her research areas include eating behaviour and obesity, communication and women's health, and she utilizes a range of quantitative and qualitative methodologies. Central to her research is the location of behaviours within their social context and an exploration of how this context creates and re-creates the meaning of such behaviours. 